J. Lake Sci. (湖泊科学), 2014, 26(6): 837-843

http://www. jlakes. org. E-mail : jlakes@niglas.ac.cn

(C) 2014 by Journal of Lake Sciences

\title{
疏浚对巢湖重污染入湖河流沉积物中污染物赋存及释放的影响"
}

\author{
王广召 ${ }^{1}$,方 涛 $^{2 * *}$, 唐 巍 $^{2}$,司马小峰 ${ }^{2}$ \\ ( 1 : 武汉理工大学资源与环境工程学院, 武汉 430070) \\ (2:中国科学院水生生物研究所,武汉 430072)
}

\begin{abstract}
摘 要: 以巢湖重污染人湖河流双桥河为研究对象, 研究了底泥疏浚对水质以及沉积物中总氮、总磷和有机质的短期影 响及长期效应. 结果表明, 双桥河水质的季节变化显著, 受上游城市污水及周边面源污染的影响, 疏浚对水质改善作用不 明显. 表层沉积物中总氮、总磷及有机质含量在疏浚结束后 1 个月有所降低,但是 2 年后分别回复到疏浚前的 $189.77 \%$ 、 $111.62 \%$ 和 $152.87 \%$. 疏浚结束 2 年后, 沉积物中磷主要以䥻磷和有机磷的形式存在,铅磷和铁磷的含量较少,弱结合态 磷的含量最低; 但是表层沉积物中的弱结合态磷、铝磷和铁磷结合态磷含量较疏浚前分别升高了 $728.32 \% 、 13.52 \%$ 和 $37.73 \%$,并呈现出表层富集现象, 存在较高的污染物释放风险. 这可能是由沉积环境改变、外源污染未得到有效控制引 起的. 因此,为了维持疏浚的长期效果,应该对外源污染源进行有效控制.
\end{abstract}

关键词: 底泥疏浚; 双桥河; 磷; 化学形态; 长期效应; 巢湖

\section{Long-term effects of dredging on pollutant distribution in sediments of a heavily polluted inflow river}

\author{
WANG Guangzhao ${ }^{1}$, FANG Tao $^{2}$, TANG Wei ${ }^{2} \&$ SIMA Xiaofeng ${ }^{2}$ \\ ( 1 : School of Resource and Environmental Engineering, Wuhan University of Technology, Wuhan 430070, P. R. China) \\ ( 2 : Institute of Hydrobiology, Chinese Academy of Sciences, Wuhan 430072, P. R. China)
}

\begin{abstract}
A heavily polluted inflow river of Lake Chaohu, Shuangqiao River, was dredged at April 2010. To evaluate effects of dredging on water quality, the variation of total nitrogen ( TN), total phosphorus ( TP) of the water were monitored every two months through 2010, and TN, TP, organic matter, as well as different chemical forms of phosphorus of the sediment were investigated before, after and 2 years later of the dredging activities. The results showed that Shuangqiao River received heavy pollution and the water quality changed seasonally, while did not get improved obviously by dredging, partly because of the inflow of upstream sewage and non-point pollution source. There was a significant decline of the content of TN, TP and organic matter in the upper layer of sediments after dredging, while recover to $189.77 \%, 111.62 \%$ and $152.87 \%$ compared to those before the dredging. Ca-P and OP took up the largest proportion of the total phosphorus, followed by Fe-P and Al-P, and Lab-P was the lowest after 2 years. However, a surface enrichment was observed, the contents of Lab-P, Al-P and Fe-P in the upper layer of sediments increased $728.32 \%, 13.52 \%$ and $37.73 \%$, respectively, compared to those of pre-dredging. Dynamics of phosphorus chemical forms in sediments means potential risks of internal nutrients releasing caused by dredging. This research suggested that the effective way to improve the water quality should combine dredging with external source pollution control as a whole.
\end{abstract}

Keywords: Sediment dredging; Shuangqiao River; phosphorus; chemical forms; long-term effects; Lake Chaohu

随着城市规模的不断扩大和经济的快速发展, 大量富含氮、磷等营养元素的污染物被排人城市河流, 导 致富营养化问题日益严重. 大量污染物沉积在河道中,在水体环境变化后,底泥中污染物的释放成为水体的 二次污染源, 对河道的有效治理产生重要影响 ${ }^{[1-2]}$. 在依靠河流的自净能力无法控制内源污染物释放对水体

* 国家水体污染控制与治理科技重大专项项目 (2012ZX07103-001) 资助. 2013-12-31 收稿; 2014-03-26 收修改 稿. 王广召(1988～), 男,硕士研究生;E-mail:wgzwhut@ 126.com.

** 通信作者;E-mail:fangt@ ihb. ac. cn. 
水质、生态系统的危害时, 底泥疏浚成为水体污染防治与生态修复过程中一项普遍使用的工程技术措施. 底 泥疏浚能够在短期内将污染底泥从水体中永久性去除, 同时可以有效地提高河道排污能力, 因而被认为是 河流、湖泊治理的重要工程措施 ${ }^{[34]}$. 但是随着外源污染物的输人、颗粒沉降、动力扰动、生物转化及生物积 累过程的持续作用, 内源回复现象将有可能逐步出现, 导致疏浚工程实施对水质的改善作用并不能持久, 甚 至出现污染程度加重的现象.

一般认为实施疏浚工程可以有效减少沉积物的内源负荷, 控制沉积物一水界面的磷和氨氮释放, 降低 湖泊的富营养化状态 ${ }^{[5-7]}$. Ruley 等 ${ }^{[8]}$ 对美国路易斯安那州一个城市湖泊疏浚后水质的长期研究发现, 疏浚 后的 10 年内避免了藻类的暴发和鱼类的死亡, 直到疏浚后近 20 年, 水体中的磷才回复到疏浚前的水平, 而 水体中的氮始终低于疏浚前的水平. 然而 Ryding ${ }^{[9]}$ 对瑞典 Trehörningen 湖底泥疏浚野外跟踪发现, 疏浚后 初期对内源磷有较好的控制作用, 但是两年后磷浓度和藻类生物量都回复到疏浚前的水平. 同时刘华丽 等 ${ }^{[10]}$ 认为湖泊内源污染的主要贡献者是长期悬浮在水体中的有机碎屑, 而疏浚只能去除少量沉积在湖底的 有机碎屑, 故疏浚无法消除内源污染. 目前, 研究主要集中于疏浚引起的沉积物环境变化及对生物群落的影 响 ${ }^{[1-12]}$, 关于河流沉积物疏浚引起沉积物营养物质释放长期影响的研究较少.

目前, 对疏浚改善水体水质的长效性认识不一, 对于底泥疏浚能否从根本上改善水环境仍然存在很大 争议. 双桥河是巢湖人湖河流中污染较为严重的城市污染控制型河流 ${ }^{[13]}$, 其人湖口距离巢湖市自来水厂取 水口仅 $500 \mathrm{~m}$, 河水污染较为严重, 水质长期为劣 $\mathrm{V}$ 类, 直接威胁着巢湖市民的饮用水安全 ${ }^{[14]}$. 为了改善水 质并提高河道排洪能力, 当地政府于 2010 年 4 月对双桥河实施了底泥疏浚工程. 为了探明底泥疏浚改善水 体水质的效果, 选取了 3 个河流断面, 分别在疏浚前和疏浚后研究了水体中的氮、磷以及沉积物中总氮、总 磷、有机质和磷形态变化, 以此研究疏浚对水质及内源污染物释放的短期和长期影响, 为类似河流的生态治 理提供依据.

\section{1 材料和方法}

\section{1 研究区域概况}

双桥河位于巢湖北岸东侧, 巢湖市西郊, 全长约 $1.45 \mathrm{~km}$, 平均宽度为 $32 \mathrm{~m}$, 是巢湖污染最严重的 4 条人 湖河流之一. 双桥河由巢湖市防洪渠及众多农田灌溉汇水而成, 市区生活污水及流域内工业废水均经该河 道排人巢湖 ${ }^{[14]}$. 双桥河在丰水期是巢湖市区的排水道, 而在枯水期则成为周边的排水沟. 研究区内,除农业 面源污染外, 周边生活污水和工业废水通过 4 个排污口进人双桥河, 其中排污口 1 位于张岗桥下游 $30 \mathrm{~m}$ 处, 排污口 $2 、 3$ 穿过铁路涵洞, 于断面 B 上游排人河中, 排污口 4 位于断面 B 下游 (图 1). 断面 $\mathrm{A}$ 以上为西排洪 沟, 属于城市河段, 主要受纳城市污水, 以下为双桥河. 西排洪沟上游来水是双桥河的主要水源, 也是污染物 质的重要来源. 双桥河段两岸为农田, 主要受面源污染的影响. 疏浚前, 由于双桥河水质不断恶化, 流域植 物多样性水平不高, 优势种以耐污种为主, 河道中空心莲子草 (Alternanthera philoxeroides) 广泛分布并大量 生长 ${ }^{[15]}$.

\section{2 采样及分析}

共设置 A、B、C 3 个监测断面, 具体如图 1 所示. 分别于 2010 年 1、3、5、7、9 和 11 月对双桥河进行水样 采集与分析. 于 2010 年 3 月和 2012 年 5 月采集柱状沉积物, 每 $5 \mathrm{~cm}$ 进行分层, 分别分为 5 层和 3 层;2010 年 5 月因考虑疏浚后沉积物层可能较薄, 因此采用彼得森采泥器采集表层约 $5 \mathrm{~cm}$ 厚的沉积物. 沉积物经冷 冻干燥、研磨、过 100 目篎后装人密封袋中, 保存于 $4^{\circ} \mathrm{C}$ 冰箱中. 分别测定 2010 年 $3 、 5$ 月表层沉积物样品和 2012 年 5 月柱状沉积物样品的不同形态磷含量; 测定 2010 年 3 月、2012 年 5 月柱状沉积物及 2010 年 5 月 表层沉积物的总氮 (TN)、总磷 (TP) 和有机质含量.

水质监测项目包括 TN、TP 含量, 分析方法参照《水和废水监测分析方法 $\rangle^{[16]}$. 沉积物 TP、无机磷 ( IP) 含 量采用 SMT 分离法测定 ${ }^{[17]}$. 有机磷 (OP) 含量为 TP 与 IP 的差值. 磷的分级提取为: 称取约 $0.5 \mathrm{~g}$ 沉积物于 $50 \mathrm{ml}$ 离心管中, 加人 $1 \mathrm{~mol} / \mathrm{L} \mathrm{NH}_{4} \mathrm{Cl}(\mathrm{pH}=7)$ 提取液, 振荡 $2 \mathrm{~h}$ 后离心, 取上清液采用钿锑抗比色法测得弱结 合态磷 ( Lab-P) 含量, 剩余泥样用 $0.5 \mathrm{~mol} / \mathrm{L} \mathrm{NH}_{4} \mathrm{~F}$ 浸提 $1 \mathrm{~h}$ 测得铝结合态磷 ( Al-P), 再剩余泥样用 $0.1 \mathrm{~mol} / \mathrm{L}$ $\mathrm{NaOH}$ 浸提 $17 \mathrm{~h}$ 测得铁结合态磷 ( Fe-P) 含量, 最后泥样用 $0.5 \mathrm{~mol} / \mathrm{L} \mathrm{H}_{2} \mathrm{SO}_{4}$ 浸提 $1 \mathrm{~h}$ 测得钙结合态磷 ( Ca-P) 
含量 ${ }^{[18]}$. 沉积物 $\mathrm{TN}$ 含量用半微量凯式法测定. 有机质含量采用灼烧法测定 ${ }^{[18]}$. 采用 Origin 8.0 软件进行 数据分析和制图, 采用 SPSS 19.0 软件进行统计分析, 设置显著水平为 0.05 .

\section{2 结果与讨论}

\section{1 双桥河水质时空变化特征}

在 2010 年整个监测时间段内双桥河河水 $\mathrm{TP}$ 含量为 $0.07 \sim 0.35 \mathrm{mg} / \mathrm{L}$, 在 5 月与 7 月低 于国家地表水 III 类标准 $(>0.2 \mathrm{mg} / \mathrm{L})$; TN 含 量为 $2.29 \sim 7.73 \mathrm{mg} / \mathrm{L}$, 为劣 $\mathrm{V}$ 类 $(>2 \mathrm{mg} / \mathrm{L})$, 在春季和冬季较高,秋季较低. 断面 $\mathrm{A}$ 与断面 $\mathrm{B} 、 \mathrm{C}$ 的 TP 和 TN 含量具有显著差异 $(P<$ 0.05 ), 沿着河流方向呈降低趋势 (图 2). 这 说明双桥河有一定的自净能力, 河道中生长的 水生植物可能起到了重要作用.

由于双桥河缺乏生态基流,其补水主要依 赖沿岸的污水排放及地表径流，周边居民的生 活污水和地表径流含有较多的氮,使得双桥河 水体中的 TN 浓度较高 ${ }^{[19]}$. 在疏浚结束后, 双 桥河水中 TP 浓度较疏浚前有所升高, 这可能 是由外源污染输人与内源污染释放共同引起 的. 双桥河小流域内有较多的农田, 在 5-7 月雨量较大, 大量的面源污染随着雨水流人双 桥河河道,使河水的 TP 浓度升高. 此外, 在 4 月份实施的底泥疏浚,一方面改变了沉积物的 表面性质,使沉积物短期内向河水释放氮、磷 活动加剧 ${ }^{[20]}$; 另一方面, 疏浚过程中水动力扰 动容易造成表层沉积物、有机碎屑和矿物质等 细小颗粒发生再悬浮, 从而造成水体中营养盐 含量短期内有所升高 ${ }^{[21]}$. 水生植物在生长过 程中可以吸收水体中大量的氮、磷等营养物 质,将其转化为自身组织, 对水体净化具有重 要作用 ${ }^{[22-24]}$. 疏浚工程使河道水生植被覆盖 度由 $40 \%$ 降低到 $5 \%$, 在疏浚结束半年后沉积 物微生态和水生植被逐渐恢复 ${ }^{[14]} .2010$ 年 7 月份以后, 随着面源污染物输人的降低以及河 道中水生植被的逐渐恢复, 河水中的污染物浓 度又有所降低.

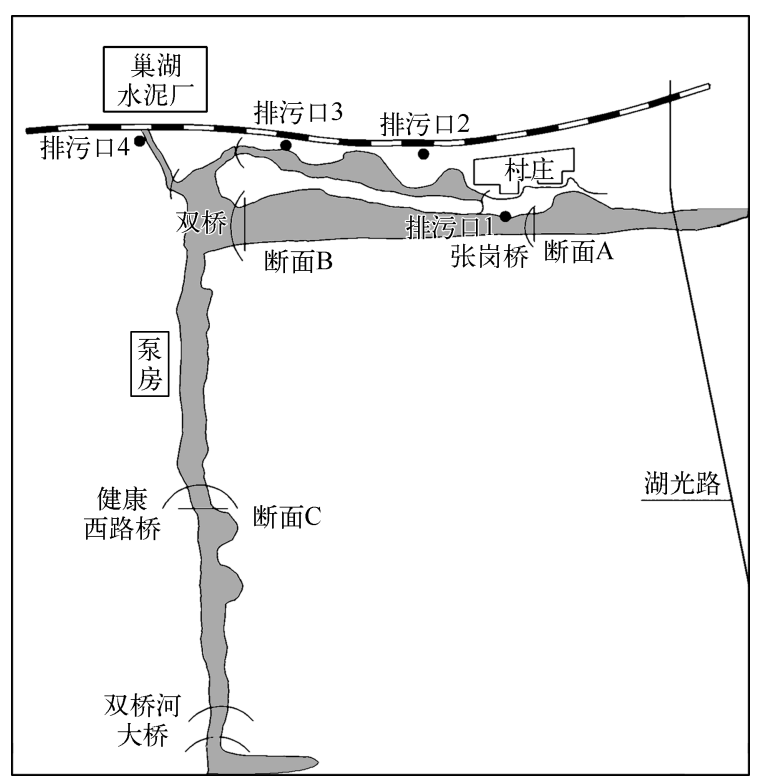

图 1 双桥河监测断面分布

Fig. 1 Location of monitoring sections in Shuangqiao River

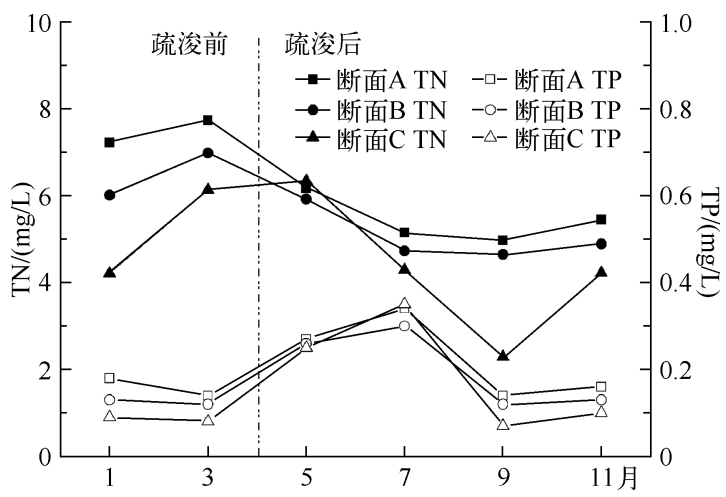

图 2 双桥河 3 个监测断面河水 $\mathrm{TN}$ 、 $\mathrm{TP}$ 含量的季节变化

Fig. 2 Seasonal variation of the TN, TP concentrations of the three monitoring sections in Shuangqiao River

\section{2 底泥疏浚对沉积物中氮、磷及有机质含量的影响}

疏浚前 (2010 年 3 月), 双桥河 3 个监测断面的 TP 含量为 $0.30 \sim 1.95 \mathrm{~g} / \mathrm{kg}$, 且随着深度增加呈降低的 趋势; 疏浚结束后 (2010 年 5 月), 3 个监测断面的 TP 含量为 $0.51 \sim 1.18 \mathrm{~g} / \mathrm{kg}$, 与疏浚前相比有明显降低; 疏浚 2 年后 $(2012$ 年 5 月), 3 个监测断面的 TP 含量为 $0.92 \sim 1.66 \mathrm{~g} / \mathrm{kg}$, 较疏浚结束时有显著上升. 疏浚 前, 双桥河 3 个监测断面的 TN 含量为 $1.58 \sim 2.39 \mathrm{~g} / \mathrm{kg}$, 相同层之间的 TN 含量近似; 疏浚后, 双桥河 $\mathrm{A} 、 \mathrm{~B} 、 \mathrm{C}$ 监测断面的 TN 含量分别为 $0.61 、 2.07 、 1.55 \mathrm{~g} / \mathrm{kg}$; 疏浚 2 年后, 3 个监测断面 TN 含量较疏浚前均显著上升 $(P<0.05)$, 在 $2.27 \sim 5.26 \mathrm{~g} / \mathrm{kg}$ 之间. 对有机质而言, 疏浚前含量为 $33.96 \sim 67.45 \mathrm{~g} / \mathrm{kg}$; 疏浚后断面 $\mathrm{A}$ 的 


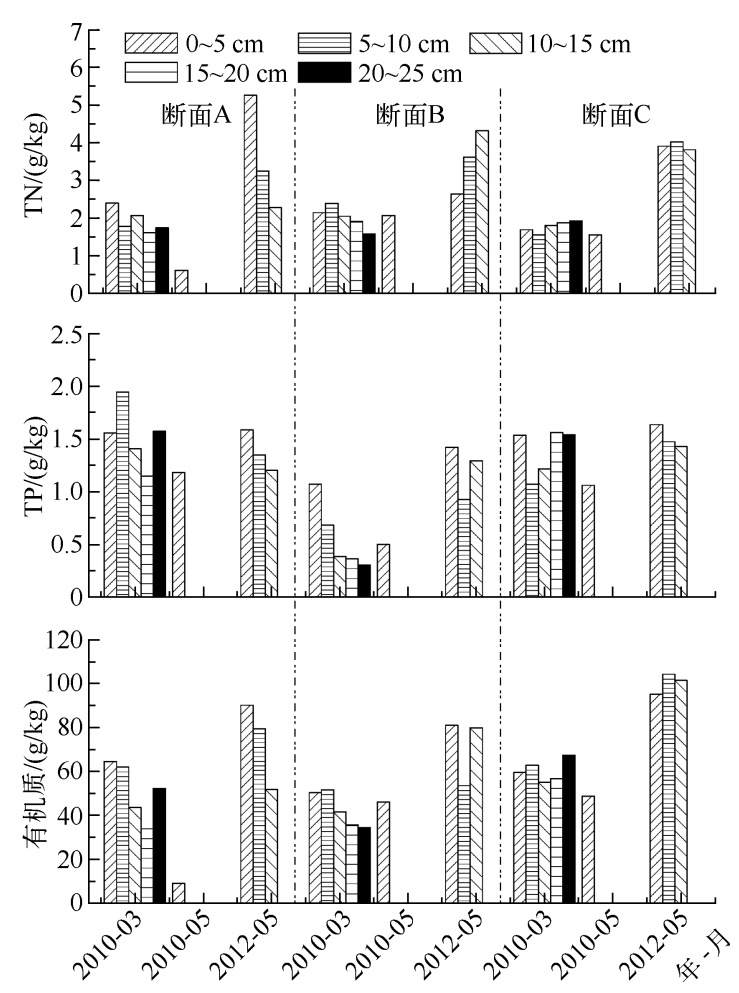

图 3 疏浚前后双桥河 3 个监测断面 沉积物中污染物含量的变化

Fig. 3 Variation of pollutants in the sediment cores of three monitoring sections in Shuangqiao River before and after dredging
有机质含量降低至 $9.06 \mathrm{~g} / \mathrm{kg}$, 断面 B 和断面 C 的有机质含量降低不明显, 分别为 46.18 和 $48.77 \mathrm{~g} / \mathrm{kg}$; 疏浚 2 年后, 3 个监测断面的有机质 含量差别较大, 在 $51.74 \sim 104.20 \mathrm{~g} / \mathrm{kg}$ 之间, 均 比疏浚前显著升高 $(P<0.05)$ ( 图 3 ).

在疏浚前, 双桥河沉积物的 TN、TP、有机质 含量随着深度的增加呈下降趋势, 在疏浚结束 后, 沉积物中的污染物含量较疏浚前降低, 可见 通过疏浚去除表层沉积物能够快速降低沉积物 的污染物含量, 降低污染物释放风险. 然而在疏 浚结束较长一段时间 (2 年) 后, 沉积物中 $\mathrm{TP} 、 \mathrm{TN}$ 和有机质含量再次达到较高的水平, 有的甚至比 疏浚前的含量还要高, 表层沉积物中的 TN、TP 和有机质的平均含量分别回复到疏浚前的 $189.77 \% 、 111.62 \%$ 和 $152.87 \%$. 这可能是由于 疏浚去除表层沉积物后, 深层沉积物直接与河水 接触, 改变了原有的释放一吸收平衡, 深层污染 物向上层迁移, 使表层污染物含量再次升高. 此 外, 沉积物中污染物含量的再次升高, 也可能与 外源污染输人及水生植物残体在沉积物表面的 积累有关 ${ }^{[25]}$. 周围区域的土壤中营养盐含量较 高, TP、TN 和有机质含量分别为 $1.58 、 1.75$ 和 $70.84 \mathrm{~g} / \mathrm{kg}$, 外源面源污染随着雨水冲刷也可能 使沉积物中的污染物含量升高 ${ }^{[26]}$. 在监测的 1 年时间内, 双桥河河水受 TN 污染严重 (图 2), 这 可能是由上游污水和周边废水中的污染物在沉 积物表面的再次积累引起的. 第 3 次采样是在

疏浚结束 2 年后, 动、植物残体在沉积物表面降解积累以及地表径流带人的颗粒物在河道底部沉积, 也会引 起沉积物 TN 和有机质含量的升高.

\section{3 疏浚对沉积物中各形态磷含量的影响}

2.3.1 表层沉积物 沉积物中不同形态磷的迁移能力不同, 磷形态是影响沉积物磷吸附和释放的内因. 双 桥河 3 个监测断面的表层沉积物中 Lab-P 平均含量在疏浚前为 $3.92 \mathrm{mg} / \mathrm{kg}$, 疏浚结束后为 $0.72 \mathrm{mg} / \mathrm{kg}$, 疏浚 2 年后高达 $32.47 \mathrm{mg} / \mathrm{kg}$, 与疏浚前相比升高了 $728.32 \%$; 表层沉积物中的 $\mathrm{Fe}-\mathrm{P}$ 平均含量在疏浚前为 42.67 $\mathrm{mg} / \mathrm{kg}$, 疏浚后为 $15.15 \mathrm{mg} / \mathrm{kg}$, 疏浚 2 年后为 $58.77 \mathrm{mg} / \mathrm{kg}$, 与疏浚前相比大约升高了 $37.73 \% ; \mathrm{Al}-\mathrm{P}$ 平均含 量在疏浚前为 $155.33 \mathrm{mg} / \mathrm{kg}$, 疏浚后为 $136.22 \mathrm{mg} / \mathrm{kg}$, 疏浚 2 年后为 $176.33 \mathrm{mg} / \mathrm{kg}$, 与疏浚前相比升高了大 约 $13.52 \%$ (图 4). 沉积物中的 Lab-P 含量较低, 但是较易释放到水体中被浮游动植物吸收, 产生水华, 不利 于河水水质改善. $\mathrm{Fe}-\mathrm{P}$ 和 $\mathrm{Al}-\mathrm{P}$ 是与 $\mathrm{Fe} 、 \mathrm{Mn} 、 \mathrm{Al}$ 氧化物及氢氧化物结合的磷, 为生物易利用的活性磷成分, 基 本可以反映内源磷的潜在释放量, 其含量可以作为污染的指标之一. 在疏浚刚结束时, 表层沉积物中的 LabP、Al-P 和 Fe-P 含量都降低, 表明深层沉积物中这 3 种结合态磷的含量较低, 去除表层沉积物能够能快速降 低沉积物磷释放风险. 但是在疏浚结束 2 年后沉积物中的 Lab-P A Al-P 和 Fe-P 含量较疏浚前升高, 表明随着 时间的推移和沉积环境的变化, 沉积物中的磷向铁、铝结合态磷转化. 因此长期来看, 通过疏浚降低双桥河 沉积物磷的释放具有不确定性.

沉积物中 $\mathrm{Ca}-\mathrm{P}$ 和 OP 含量与有机污染物的含量相关, 是沉积物中较难被生物利用的惰性磷组分. Ca-P 平均含量在疏浚前为 $1046.67 \mathrm{mg} / \mathrm{kg}$, 疏浚结束时为 $856.67 \mathrm{mg} / \mathrm{kg}$, 在疏浚 2 年后为 $881.33 \mathrm{mg} / \mathrm{kg}$, 疏浚使 
沉积物中的 Ca-P 含量与疏浚前相比大约下降了 $15.79 \%$. OP 平均含量在疏浚前为 $343.17 \mathrm{mg} / \mathrm{kg}$, 疏浚后为 $357.67 \mathrm{mg} / \mathrm{kg}$, 疏浚结束 2 年后为 $293.33 \mathrm{mg} / \mathrm{kg}$, 与疏浚前相比下降了 $14.52 \%$ (图 4). 有机磷是沉积物中 重要的磷蓄积库, 可以用来粗略估计有机质的生成和降解, 是一种优于 TP 的可指示富营养化过程的指 标 ${ }^{[27]}$. 疏浚 2 年后表层沉积物中的 OP 含量降低,表明疏浚后双桥河富营养化趋势在减缓. 且沿着河流方 向, 沉积物中的 $\mathrm{OP}$ 含量有下降的趋势, 表明沿着河流方向富营养化状况降低, 这与河流水质监测数据相符.

2.3 .2 柱状沉积物 疏浚 2 年后, 双桥河的柱状沉积物中 Lab-P 含量为 $16.71 \sim 53.52 \mathrm{mg} / \mathrm{kg}$, 随深度变化不 明显. 这是因为在沉积物表层有机磷发生强烈的矿化降解, 向孔隙水中释放较多的溶解性磷, 同时较多的磷 酸根被沉积物颗粒吸附, 而在深层还原性环境中,矿化作用减弱,但是吸附性磷的解吸增强,使 Lab-P 含量随 着深度变化基本不发生变化 ${ }^{[28]}$.

断面 A 的 Al-P 含量随着深度的增加, 由 $220.68 \mathrm{mg} / \mathrm{kg}$ 降低至 $152.11 \mathrm{mg} / \mathrm{kg}$; 断面 B 随着深度变化 Al-P 含量先降低后升高, $0 \sim 5 、 5 \sim 10$ 和 $10 \sim 15 \mathrm{~cm}$ 处分别为 $256.32 、 93.43$ 和 $164.86 \mathrm{mg} / \mathrm{kg}$; 断面 C 随着深度的 增加, Al-P 含量从 $61.85 \mathrm{mg} / \mathrm{kg}$ 增加至 $301.94 \mathrm{mg} / \mathrm{kg}$. 断面 A 和断面 B 的 Al-P/TP 在第 3 层分别为 $12.65 \%$ 和 $12.81 \%$, 近似相等,表明在深层沉积物中的 Al-P 含量趋于稳定. 疏浚后沉积物中 Fe-P 呈现出表层富集, 断面 A 的 Fe-P 含量随着深度的增加由 $58.62 \mathrm{mg} / \mathrm{kg}$ 降低至 $36.29 \mathrm{mg} / \mathrm{kg}$, 断面 B 由 $100.23 \mathrm{mg} / \mathrm{kg}$ 降低至 $81.48 \mathrm{mg} / \mathrm{kg}$, 断面 C 由 $37.37 \mathrm{mg} / \mathrm{kg}$ 降低至 $26.82 \mathrm{mg} / \mathrm{kg}$ (图 5). 在沉积物埋藏过程中, 沉积物表层形成铁 和锰的表面氧化层, 在深层厌氧还原环境中, 沉积磷矿物还原形成磷酸盐并通过孔隙水向上扩散迁移; 向上 迁移转化的溶解磷酸盐又被表层氧化层中铁、锰氧化物强烈吸附, 因此 Fe-P 在沉积物表层富集. 在疏浚结 束 2 年后,断面 $\mathrm{A}$ 和断面 B 的表层沉积物中的 Al-P 和 Fe-P 含量均高于深层,而 Al-P 和 Fe-P 在厌氧条件下 可以释放出来, 对水质产生不利影响. 不同断面表层沉积物中的 Al-P 和 Fe-P 含量不同,断面 B 大于断面 A 和断面 $\mathrm{C}$ (图 5), 表明断面 $\mathrm{B}$ 污染物释放风险较高, 这可能与断面间排污口的差异有关.

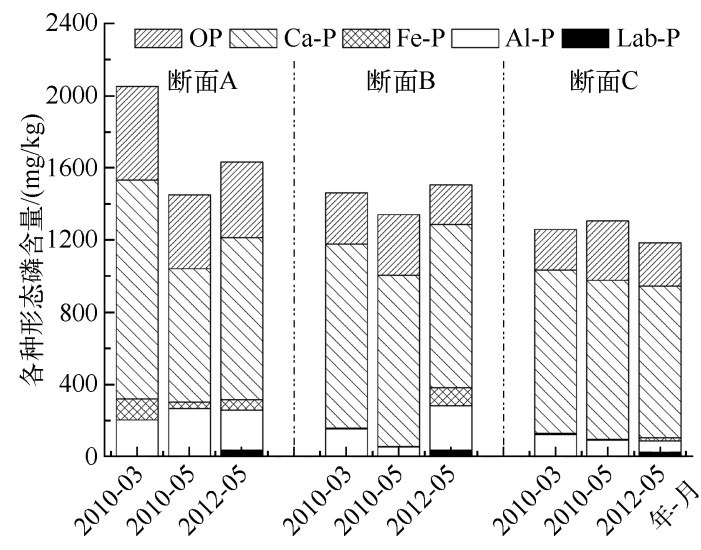

图 4 疏浚前后双桥河 3 个监测断面表层 沉积物中各形态磷含量的变化

Fig. 4 Variation of phosphorus fractions of surface sediments of three monitoring sections in Shuangqiao River before and after dredging

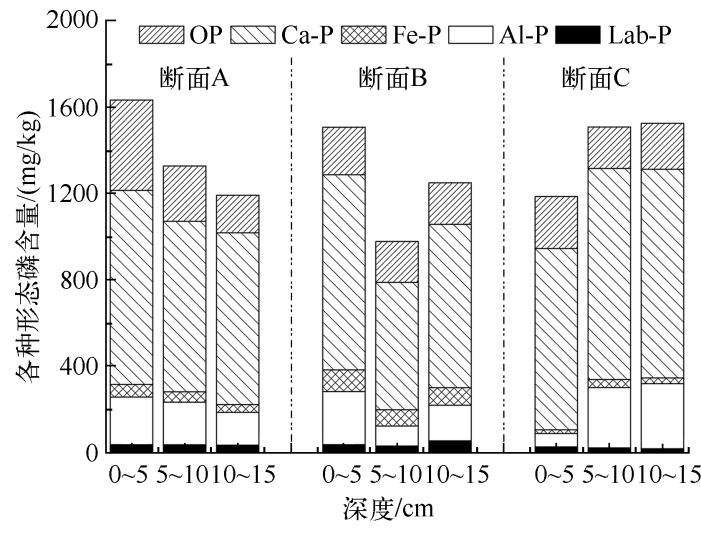

图 5 疏浚 2 年后双桥河 3 个监测断面柱状沉积物 中各形态磷含量的变化

Fig. 5 Variation of phosphorus fractions of sediment cores at three monitoring sections in Shuangqiao River 2 years later of dredging

在疏浚结束 2 年后, 沉积物中的 TP 含量仍然很高, 为 $0.92 \sim 1.63 \mathrm{~g} / \mathrm{kg}$, 并且主要以较难被生物利用的 Ca-P 和 OP 的形态存在, 分别占总量的 $51.43 \% \sim 67.83 \%$ 和 $13.06 \% \sim 26.42 \%$ (图 5 ). 3 个断面的 Ca-P/TP 值都大于 $50 \%$, 表明 $\mathrm{Ca}-\mathrm{P}$ 为沉积物中磷的主要存在形态. Ca-P 含量与有机质含量有关, 浮游动植物是沉积 物中 Ca-P 的主要来源之一 ${ }^{[27]}$. 疏浚结束 2 年后, 沉积物 $\mathrm{OP}$ 含量随着深度增加而降低, $10 \sim 15 \mathrm{~cm}$ 沉积物中 $\mathrm{OP}$ 占 TP 比例趋于稳定, 大约为 $15 \%$. 沉积物中的 OP 主要来源于农业面源污染以及上覆水中生物残屑的 积累, 并且可以在微生物作用下转化为其他形态的磷而释放到上覆水中. 这表明在疏浚后, 面源污染物的输 
人是双桥河沉积物中污染物含量升高的一个重要原因. 断面 $\mathrm{A}$ 的 $\mathrm{OP}$ 含量较断面 $\mathrm{B}$ 和断面 $\mathrm{C}$ 高, 这可能是 由于断面 $\mathrm{A}$ 除了附近排污口排放的污水外, 还受纳上游排放的城市生活污水, 污染物浓度较高.

\section{4 沉积物中的 TOC/TN}

很多研究表明, 沉积物中的 TOC/TN 值可以有效指示沉积物中的有机质来源. 因为水生植物含有较多 的蛋白质, 其 TOC/TN 值一般小于 10 ; 而陆源有机质因为富含腐殖质, 其 TOC/TN 值通常为 $14 \sim 30^{[29-31]}$. 此 外, 水体有机质的降解也会使沉积物的 TOC/TN 值升高. 在疏浚前后, 除个别层外, 3 个监测断面沉积物的 TOC/TN 值大都大于 10 , 说明双桥河水质污染源主要为外源污染物, 在疏浚结束后仍然应该将控制外源污 染作为改善双桥河水质的主要措施. 断面 A 和断面 C 的 TOC/TN 值均较高, 而断面 B 的 TOC/TN 值较低 (表 1), 这可能与断面间排污口的差异及河道中生长的植物数量有关. 相对于断面 $\mathrm{A}$ 和断面 $\mathrm{C}$, 断面 $\mathrm{B}$ 的内 源污染较多, 外源污染较少, 同时断面 B 处水生植物生长较多. 断面 A 附近排污口的污水和上游污水, 断面 $\mathrm{C}$ 上游排污口的大量生活污水和工业废水, 带来较多的外源污染, 使得断面 A 和断面 C 的 TOC/TN 值较高.

\section{表 1 双桥河 3 个监测断面沉积物中的 TOC/TN}

Tab. 1 TOC/TN in sediment of three monitoring sections of Shuangqiao River

\begin{tabular}{|c|c|c|c|c|c|c|c|c|c|}
\hline \multirow{2}{*}{$\begin{array}{l}\text { 断面 } \\
\text { 深度 }\end{array}$} & \multicolumn{3}{|c|}{ 断面 A } & \multicolumn{3}{|c|}{ 断面 B } & \multicolumn{3}{|c|}{ 断面 C } \\
\hline & $\begin{array}{c}2010 \text { 年 } \\
3 \text { 月 }\end{array}$ & $\begin{array}{c}2010 \text { 年 } \\
5 \text { 月 }\end{array}$ & $\begin{array}{c}2012 \text { 年 } \\
5 \text { 月 }\end{array}$ & $\begin{array}{c}2010 \text { 年 } \\
3 \text { 月 }\end{array}$ & $\begin{array}{c}2010 \text { 年 } \\
5 \text { 月 }\end{array}$ & $\begin{array}{c}2012 \text { 年 } \\
5 \text { 月 }\end{array}$ & $\begin{array}{c}2010 \text { 年 } \\
3 \text { 月 }\end{array}$ & $\begin{array}{c}2010 \text { 年 } \\
5 \text { 月 }\end{array}$ & $\begin{array}{c}2012 \text { 年 } \\
5 \text { 月 }\end{array}$ \\
\hline $0 \sim 5 \mathrm{~cm}$ & 15.62 & 13.00 & 9.34 & 13.68 & 12.96 & 17.81 & 20.49 & 18.21 & 14.13 \\
\hline $5 \sim 10 \mathrm{~cm}$ & 20.22 & - & 14.18 & 12.52 & - & 8.59 & 23.36 & - & 15.03 \\
\hline $10 \sim 15 \mathrm{~cm}$ & 12.24 & - & 12.13 & 11.74 & - & 10.71 & 17.78 & - & 15.45 \\
\hline $15 \sim 20 \mathrm{~cm}$ & 12.19 & - & - & 10.85 & - & - & 17.56 & - & - \\
\hline $20 \sim 25 \mathrm{~cm}$ & 17.36 & - & - & 12.62 & - & - & 20.43 & - & - \\
\hline
\end{tabular}

\section{3 结论}

1 ) 疏浚去除了富含污染物的表层沉积物, 在短期内能够降低沉积物对水质的影响;2)疏浚后, 随着时间 的推移, 沉积物中 Lab-P、Al-P 和 Fe-P 含量较疏浚前升高. 深层沉积物中污染物向上层迁移, 外源污染物的 再次积累, 使 Al-P 和 Fe-P 呈现出表层富集现象, 磷的潜在释放风险加大;3) 疏浚前后, 双桥河沉积物中各形 态磷的含量及 TOC/TN 值变化均表明外源污染仍是双桥河的一个重要污染源. 因此, 需要将疏浚、外源污染 控制及防止水生植物过度生长相结合,才能有效地改善受污染河流的水质状况.

\section{4 参考文献}

[ 1 ] Sun YB, Zhou QX, Xie XK et al. Spatial, sources and risk assessment of heavy metal contamination of urban soils in typical regions of Shenyang, China. Journal of Hazardous Materials, 2010, 174 (1) :455-462.

[ 2 ] Wu M, Sun XM, Huang SL et al. Laboratory analyses of nutrient release processes from Haihe River sediment. International Journal of Sediment Research, 2012, 27(1) :61-72.

[ 3 ] Wang J, Liu XD, Lu J. Urban river pollution control and remediation. Procedia Environmental Sciences, 2012, (13): $1856-1862$.

[ 4 ] Zhong JC, Fan CX, Zhang L et al. Significance of dredging on sediment denitrification in Meiliang Bay, China: A year long simulation study. Journal of Environmental Sciences, 2010, 22 (1):68-75.

[ 5 ] Zhang SY, Zhou QH, Xu D et al. Effects of sediment dredging on water quality and zooplankton community structure in a shallow of eutrophic lake. Journal of Environmental Sciences, 2010, 22 (2) :218-224.

[ 6 ] 钟继承, 刘国锋, 范成新等. 湖泊底泥疏浚环境效应: I. 内源磷释放控制作用. 湖泊科学, 2009, 21(1):84-93.

[ 7 ] 钟继承, 刘国锋, 范成新等. 湖泊底泥疏浚环境效应: II. 内源氮释放控制作用. 湖泊科学, 2009, 21 (3): $335-344$.

[ 8 ] Ruley JE, Rusch KA. An assessment of long-term post-restoration water quality trends in a shallow, subtropical, urban hy- 
pereutrophic lake. Ecological Engineering, 2002, 19(4):265-280.

[ 9 ] Ryding SO. Lake Trehörningen restoration project. Changes in water quality after sediment dredging. Sediment/Freshwater Interaction, 1982, 9:549-558.

[10］刘华丽, 曹秀云, 宋春雷等. 沉积物疏浚技术在富营养化湖泊修复中的应用. 环境污染与防治, 2012, 34(2):8791.

[11] Fischer J, Paukert C, Daniels M. Fish community response to habitat alteration: impacts of sand dredging in the Kansas River. Transactions of the American Fisheries Society,2012, 141(6) :1532-1544.

[12] Jonge MD, Belpaire C, Geeraerts C et al. Ecological impact assessment of sediment remediation in a metal-contaminated lowland river using translocated zebra mussels and resident macroinvertebrates. Environmental Pollution, 2012, 171 : 99-108.

[13］王书航，姜 霞，金相灿. 巢湖人湖河流分类及污染特征分析. 环境科学, 2011, 32(10):2834-2839.

[14] 司马小峰, 朱文涛, 方 涛. 疏浚对巢湖双桥河水环境容量的影响. 环境工程学报, 2012, 6(7):2207-2214.

[15] 祝国荣, 倪乐意, 方 涛等. 巢湖东湖区人湖河流的水生植被群落结构和区系特征及其与环境因子的关系. 应用 与环境生物学报, 2012, 18(6):889-896

[16] 国家环境保护总局《水和废水监测分析方法》编委会. 水和废水监测分析方法:第 4 版. 北京: 中国环境科学出版 社, 2002.

[17] Ruban V, Brigault S, Demare D et al. An investigation of the origin and mobility of phosphorus in freshwater sediments from Bort-Les-Orgues Reservoir, France. Journal of Environmental Monitoring, 1999, 1(4) :403-407.

[18］鲍士旦. 土壤农化分析:第 3 版. 北京:中国农业出版社, 1999.

[19］宋家永, 李英涛, 宋 宇等. 农业面源污染的研究进展. 中国农学通报, 2010, 26(11):362-365.

[20] 张 丹, 张 勇, 何 岩等. 河道底泥环保疏浚研究进展. 净水技术, 2011, 30(1):1-3.

[21] Nayar S, Miller D, Hunt A et al. Environmental effects of dredging on sediment nutrients, carbon and granulometry in a tropical estuary. Environmental Monitoring and Assessment, 2007, 127(1/2/3):1-13.

[22] Zhao FL, Xi S, Yang XE et al. Purifying eutrophic river waters with integrated floating island systems. Ecological Engineering, 2012, 40:53-60.

[23] Lu Q, He ZL, Graetz DA et al. Phytoremediation to remove nutrients and improve eutrophic stormwaters using water lettuce( Pistia stratiotes L. ). Environmental Science and Pollution Research, 2010, 17(1):84-96.

[24] Rectenwald LL, Drenner RW. Nutrient removal from wastewater effluent using an ecological water treatment system. Environmental Science and Technology, 2000, 34(3) :522-526.

[25] 俞海桥, 王俊川, 邓家添等. 疏浚及水生植被重建对西五里湖沉积物有机质的影响. 农业环境科学学报, 2009,28 (10) $: 1-5$.

[26] 司马小峰. 巢湖双桥河水污染特征及水环境容量研究 [学位论文]. 北京: 中国科学院大学, 2011.

[27] Zhang RY, Wu FC, Liu CQ et al. Characteristics of organic phosphorus fractions in different trophic sediments of lakes from the middle and lower reaches of Yangtze River region and Southwestern Plateau, China. Environmental Pollution, $2008,152(2): 366-372$.

[28] 刘 峰, 高云芳, 王立欣等. 水域沉积物氮磷赋存形态和分布的研究进展. 水生态学杂志, 2011, 32(4): 137-144.

[29] 李绪录, 周毅频, 厦华永. 大鹏湾表层沉积物中碳、氮、磷的多年调查结果和有机质来源分析. 环境科学学报, $2012,32(5): 1113-1119$.

[30］李 苗, 藏淑英, 张 策等. 那什那泡沉积物氮磷有机质污染特征及评价. 地理科学, 2013, 33(12):1531-1536.

[31] Batayneh AT. Toxic(aluminum, beryllium, boron, chromium and zinc) in groundwater: health risk assessment. International Journal of Environmental Science and Technology, 2012, 9(1):153-162. 